\title{
Mammary Fibroepithelial Hyperplasia in a Male Cat
}

\author{
Giovanna Lapkoski Bonatto', Victoria Gariba e Silva', Lucas Jocemir Favero², Natália Noreika Kano', \\ Renato Silva de Sousa' \& Vinicius Gonzalez Peres Albernaz'
}

\begin{abstract}
Background: Feline mammary hyperplasia (FMH) is a benign disease that commonly affects young females, once it is caused by the exaggerated stimulation of endogenous or exogenous progestogen. FMH leads to acute edema and inflammation of the mammary glands and frequently evolve to ulcerations, secondary infections, and systemic clinical signs. Even though it is rare in male cats, progesterone therapy or an unknown endogenous source of hormone can cause the disease. This report aims to describe a case of FMH in a male feline with no history of hormonal treatment and treated with radical surgical resection.

Case: A 7-month-old intact male domestic shorthair cat was presented due to acute onset of generalized mammary tumors which had progressed for 18 days. Tumors size had $5 \mathrm{~cm}$ large in diameter, symmetric, bilateral, and affected all mammary glands. The tissue was firm, hyperemic, and ulcerated. FMH was initially suspected but with a differential diagnosis for mammary adenocarcinoma. Except for pain on tumor palpation, there was no other clinical abnormality. Survey thoracic radiographs and abdominal ultrasound did not find signs of metastasis or hermaphroditism. Fine-needle aspirate biopsy and further cytological examination were inconclusive. Surgical resection through a single-stage bilateral total mastectomy and reconstruction using a left flank fold flap was elected. There were no intraoperative complications and the cat recovered well, with good healing and no clinical signs 21 days after the surgery. Histological examination of the mammary glands confirmed the diagnosis of FMH due to the non-neoplastic characteristics and tissue's benign biological behavior. Eleven months after diagnosis, the cat was asymptomatic.

Discussion: The FMH frequently affects young females and is associated with gestational periods, the end of the estrous cycle, and, most commonly, hormonal therapy with synthetic progesterone. Male cats are rarely affected with or without a history of progesterone administration, which is commonly used for treatment of dermatopathies, urinary incontinence, control of behavioral changes, or mistakenly as a contraceptive. Clinical signs are the acute onset of mammary tumors with firm consistency, inflammation, ulcerated areas, absence of mammary secretion, and mobility difficulty due to local swelling. Systemic clinical signs including apathy, anorexia, fever, and dehydration can occur. The main differential diagnosis is mammary neoplasia and diagnosis is suspected by the patient's history, disease progression, and histological examination. Conservative treatment using a progesterone inhibitor, such as aglepristone, can be performed but usually take a few weeks to promote total remission, may require additional administration, and does not prevent a possible recurrence. Radical mastectomy is an alternative to late-stage disease. It was chosen to perform a single-stage bilateral mastectomy for surgical removal of the FMH in this case mainly considering that it was a male cat with no detectable progesterone source, marked swelling, and a clinical condition that could deteriorate quickly. The FMH prognosis is good when there are no secondary infections or systemic signs, making it possible to maintain quality of life after treatment. The FMH must be considered a differential diagnosis for feline mammary tumors, regardless of gender and history of progesterone administration.
\end{abstract}

Keywords: feline, hyperplasia, mastectomy. 


\section{INTRODUCTION}

Feline mammary hyperplasia (FMH) is a benign non-neoplastic disease that affects one or more mammary glands and characterizes by the rapid and disorderly proliferation of mammary stroma and duct epithelium [1,2]. FMH commonly occurs in young female cats in association with high serum progesterone concentration $[1,12]$. Cats receiving treatment with synthetic progesterone are at increased risk to develop FMH [9].

There are a few reports of FMH in male cats, most of them result of exogen progesterone administration [3,12], therefore, gender cannot rule out the differential diagnosis of FMH in cats with mammary gland swelling [10]. This report aims to describe the clinical, histological findings and surgical treatment of a male cat with a FMH unrelated to hormonal treatment.

\section{CASE}

A 7-month-old intact male domestic shorthair cat was presented due to acute onset of disseminated mammary tumors that progressively evolved for 18 days. Tumors were firm, hyperemic, ulcerated, symmetric, bilateral, and measured approximately $5 \mathrm{~cm}$ in diameter (Figure 1). FMH was initially suspected, but a differential diagnosis for mammary adenocarcinoma was considered.

The patient exhibit tenderness on palpation and had difficulty moving due to local swelling, but no other clinical sign or systemic abnormality was reported. Eventual macrometastasis or hermaphroditism was ruled out after 3-view thoracic radiographs and survey abdominal ultrasound, respectively. Fine needle aspiration biopsy and cytology was inconclusive. Medical treatment was offered, but the owner elected surgical resection through a single-stage bilateral total mastectomy followed by a left side flank fold flap (Figure 2).

Single-stage bilateral total mastectomy was performed routinely through an elliptical incision around all mammary tissue and a $\mathrm{W}$-shaped incision at the cranial aspect of the first glands. Cranial and caudal epigastric arteries and veins were double ligated using 3-0 polydioxanone (PDS). Blunt subcutaneous dissection, walking sutures, and a left flank fold flap were necessary for primary wound closure. An inverted U-shape incision was performed at the left flank fold and further dissection allowed transferring the flap for the wound bed and primary tension-free closure of the inguinal region.
The surgery went uneventfully, and the cat recovered in the intensive care unit for $24 \mathrm{~h}$ until discharged. Meloxicam ${ }^{1}(0.05 \mathrm{mg} / \mathrm{kg}$ once daily for 4 days), tramadol hydrochloride ${ }^{2}$ (4 mg/kg 3 times daily for 4 days), and clavulanate amoxicillin ${ }^{3}$ (22 mg/ $\mathrm{kg}$ twice daily for 7 days) were administered orally postoperatively. Methadone ${ }^{4}(0.2-0.3 \mathrm{mg} / \mathrm{kg})$ was administered as necessary during hospital stay. On the $21^{\text {st }}$ day postoperatively, the wound was healed, and skin sutures were removed. There was no postoperative complication, and the cat was completely recovered.

The mammary chains were histologically examined, and cells with mild to moderate anisocytosis and anisocariosis, round nucleus with dense chromatin, and conspicuous nucleolus were observed; the tissue was organized in acini separated by a marked amount of collagen-rich stroma (Figure 3). The definitive diagnosis was fibroepithelial hyperplasia due to its non-neoplastic abnormality and benign biological behavior. There were no signs of the disease 11 months after surgery

\section{DISCUSSION}

FMH commonly affects young intact female cats in gestational periods, end of the estrous cycle, or, most commonly, receiving hormonal therapy with synthetic progesterone $[1,9,12]$. Although rare in male cats, FMH can occur due to exogen progesterone administration commonly used for the treatment of dermopathies, urinary incontinence, behavioral changes, or mistakenly as a contraceptive $[3,5,12]$. The most common clinical signs are the acute onset of bilateral symmetric mammary tumors with firm consistency, inflammation, ulcerated areas, and absence of mammary secretion. FMH can also evolve to systemic clinical signs of apathy, anorexia, fever, and dehydration with or without secondary infection [11].

The present report describes a case of a 7-month-old intact male cat with no history of exogen administration of hormones that developed FMH. The occurrence of FMH in the absence of an exogen hormonal source in males is rare but was described once [6]. Mammary glands were symmetrically hyperplastic with a firm elastic consistency, signs of inflammation, skin ulceration, and no secretion on manual compression of the mammary tissue. Such characteristics were compatible with FMH and have been reported previously $[3,12]$. Unfortunately, image and laboratory 


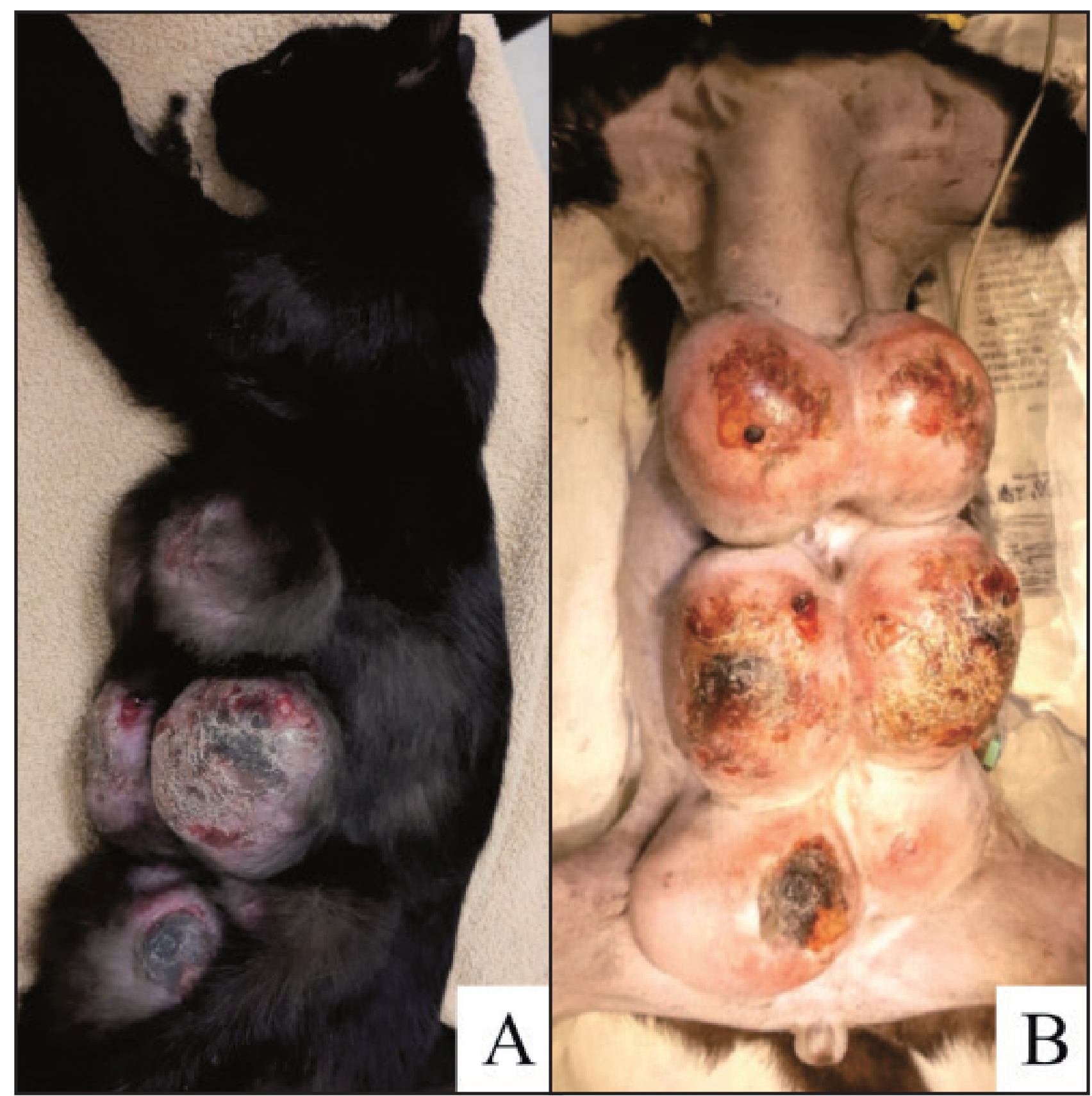

Figure 1. Generalized mammary tumor in a 7-month-old feline patient, presenting loss of anatomical morphological aspect and superficial ulcerations distributed diffusely through the mammary tissue. A- The mammary chain in lateral view. B- Animal positioned in dorsal recumbency and prepared for surgical procedure.

diagnosis failed to find a source of endogenous hormone that could be the etiology of FMH in this case.

Mammary tumors in cats are neoplastic in $80 \%$ of the cases and mainly affect old females [6]. Despite possible, the cat was unlikely to be affected by a malignant neoplastic disease since the acute onset of bilateral, symmetric, and progressive disease was not compatible. The most likely diagnosis was FMH, which was further confirmed by the benign histologic appearance of the tissue. Cats affected by FMH usually appear clinically normal without signs of pain, howe- ver, they may have mobility difficulties due to local edema [4]. In this case, the cat was alert but tenderness and difficulty in walking raised our attention that the disease was rapidly advancing for symptomatic stages. The treatment of FMH is based on removing the hormonal stimulus by interrupting the progesterone treatment and performing ovariosalpingohisterectomy (OSH) $[1,3,8]$. As it was a male, there was no possibility of OSH and the absence of exogenous hormone administration made it impossible to interrupt the treatment. Aglepristone, a progesterone inhibitor, has 


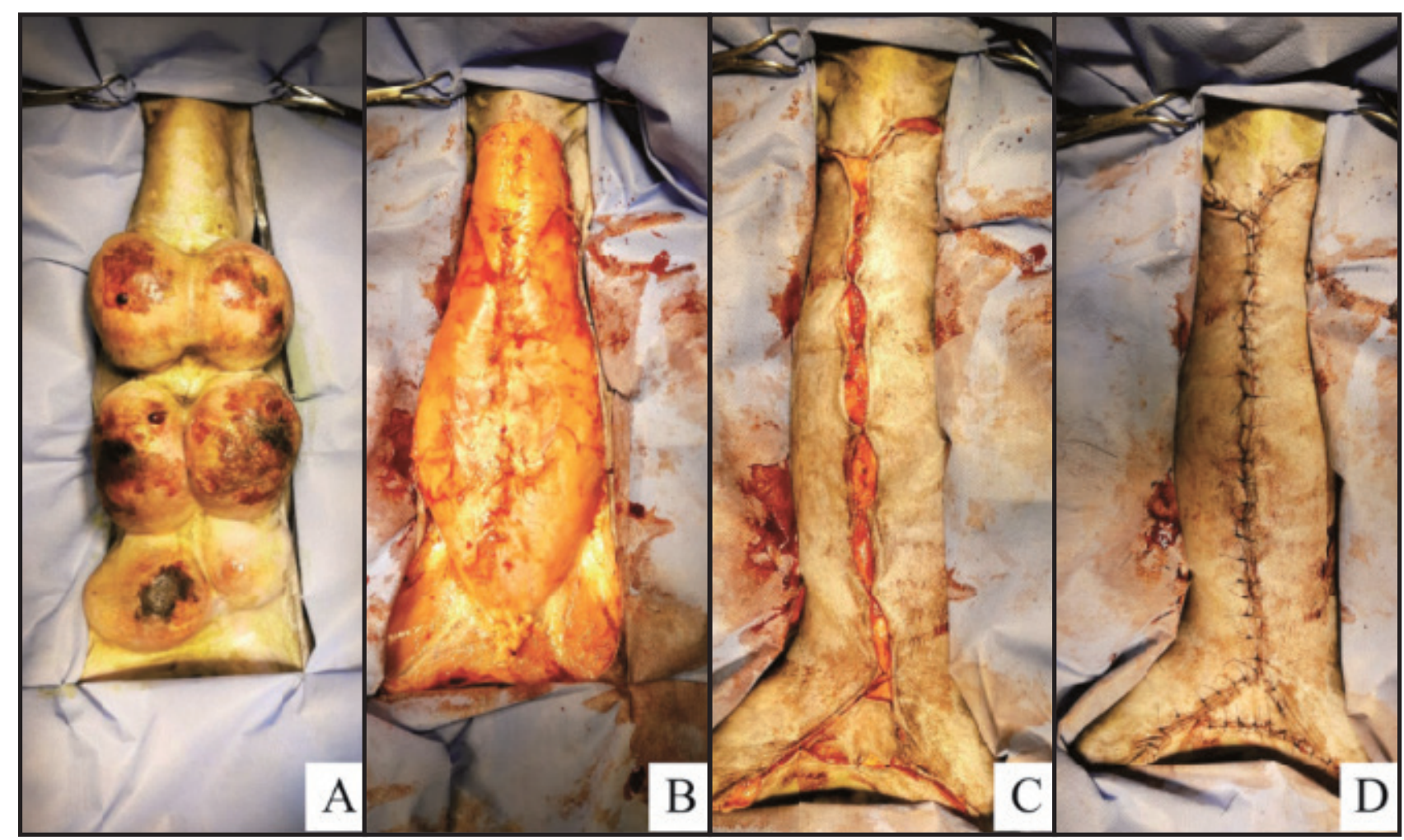

Figure 2. Bilateral total mastectomy procedure stages in a male feline. A- Bilateral nodules to be removed. B- Abdominal defect after nodules removal. C- Subcutaneous tissue approximation with left subdermal flank fold flap. D- Final appearance after skin closure.

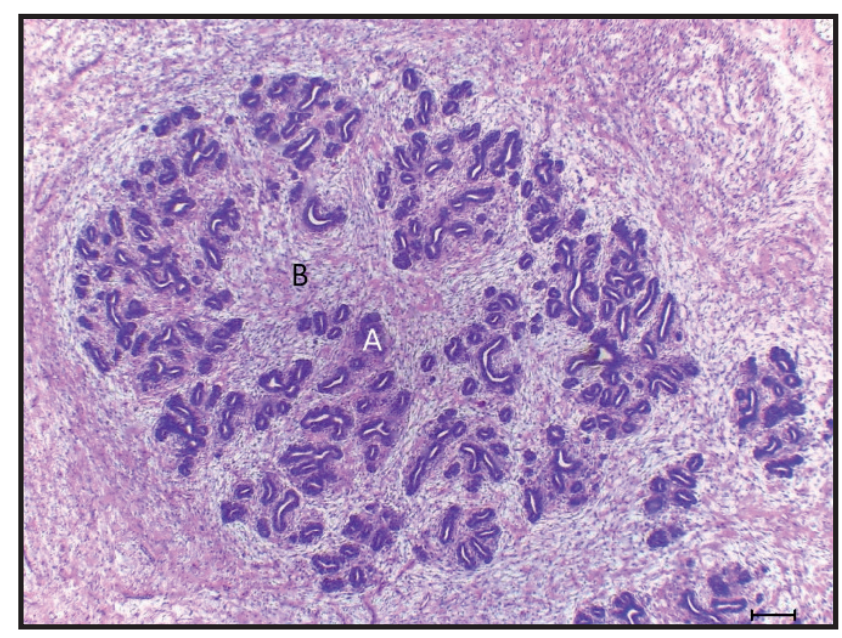

Figure 3. Mammary fibroepithelial hyperplasia in a 7-month-old male cat. A- Mammary epithelial hyperplasia of lobular ducts. B- Fibrous hyperplasia of connective tissue [10x; Bar= 4 um].

been advocated for medical treatment of FMH because it simulates a decline in progesterone concentration and inhibits the stimulation of mammary tissue growth. However, several applications may be required, and 3 to 11 weeks may be necessary for complete resolution of the mammary swelling $[1,7,9]$. Also, aglepristone does not prevent recurrences, which can happen when there are high levels of systemic progesterone, or in a further exogenous progestogen administration $[1,11]$. There was a concern among authors if treatment with aglepristone could be effective in this case due to the unknown origin of the FMH. The rapid progression of the disease to advanced lesions while in a stable clinical condition was also considered. Bilateral single-stage total mastectomy is indicated in cats with cutaneous ulceration and necrosis [11]. We elected to proceed with radical bilateral mastectomy in this case as it would provide immediate resolution of the large tumor size before local or systemic deterioration.

The prognosis of FMH is typically good, regardless of the affected gender; however, it becomes reserved in the presence of secondary infections or systemic clinical signs. Mortality is variable, and death may occur in cases with secondary complications or when the owner opts for euthanasia [8]. The prognosis of the patient was considered good, once the histological diagnosis was fibroepithelial hyperplasia and bilateral total mastectomy promoted complete resection of the hyperplasic tissue, providing early recovery and long-term quality of life to the patient.

The FMH must be considered a differential diagnosis for feline mammary tumors, regardless of gender and history of progesterone administration. Single-stage bilateral mastectomy was feasible, provided excellent recovery and long-term quality of life in this case. 


\section{MANUFACTURERS}

${ }^{1}$ Ourofino Saúde Animal. Cravinhos, SP, Brazil

${ }^{2}$ EMS. Hortolândia, SP, Brazil.

${ }^{3}$ Eurofarma Brasil. São Paulo, SP, Brazil.
${ }^{4}$ Cristália Produtos Químicos Farmacêuticos Ltda. Itapira, SP, Brazil.

Declaration of interest. The authors report no conflicts of interest. The authors alone are responsible for the content and writing of the paper.

\section{REFERENCES}

1 Filgueira K.D., Reis P.F.C.C., Macêdo L.B., Oliveira I.V.P.M., Pimentel M.M.L. \& Reche Jr. A. 2015. Caracterização clínica e terapêutica de lesões mamárias não neoplásicas em fêmes da espécie felina. Acta Veterinaria Brasilica. 9(1): 98-107. DOI: 10.21708/avb.2015.9.1.4780

2 Görlinger S., Kooistra H.S., van den Broek A. \& Okkens A.C. 2002. Treatment of fibroadenomatous hyperplasia in cats with aglépristone. Journal of Veterinary Internal Medicine. 16(6): 710-713. DOI: 10.1111/j.1939-1676.2002. tb02412.x

3 Küçükbekir Ç.N., Uçmak Z.G., Kirşan I. \& Tek Ç. 2020. A case of feline fibroepithelial hyperplasia in a male cat. Journal of Instabul Veterinary Sciences. 4(1): 8-12. DOI: 10.30704/http-www-jivs-net.691787

4 Leidinger E., Hooijberg E., Sick K., Reinelt B. \& Kirtz G. 2011. Fibroepithelial hyperplasia in an entire male cat: cytologic and histopathological features. Tierärztliche Praxis Kleintiere. 39(3): 198-202. DOI: 10.1055/s-0038-1623578

5 Loretti A.P., Ilha M.R.S., Ordás J. \& de las Mulas J.M. 2005. Clinical, pathological and immunohistochemical study of feline mammary fibroepithelial hyperplasia following a single injection of depot medroxyprogesterone acetate. Journal of Feline Medicine and Surgery. 7(1): 43-52. DOI: 10.1016/j.jfms.2004.05.002

6 Mayayo S.L., Bo S. \& Pisu M.C. 2018. Mammary fibroadenomatous hyperplasia in a male cat. Journal of Feline Medicine and Surgery Open Reports. 4(1): 1-5. DOI: 10.1177/2055116918760155

7 Nak D., Nak Y., Seyrek-Intas K. \& Kumru I.H. 2004. Treatment of feline mammary fibroadenomatous hyperplasia with aglepristone. Australian Veterinary Practitioner. 34(4): 161-162.

8 Pantoja A.R., Bastos M.M.S. \& João C.F. 2017. Hiperplasia mamária felina. Ciência Animal. 27(3): 89-98.

9 Payan-Carreira R.2013. Feline mammary fibroepithelial hyperplasia: a clinical approach. In: Insights from Veterinary Medicine. Rijeka: IntechOpen, pp.215-232.

10 Souza T.M., Fighera R.A., Langohr I.M. \& Barros C.S.L. 2002. Hiperplasia fibroepitelial mamária em felinos: cinco casos. Ciência Rural. 32(5): 891-894. DOI: 10.1590/S0103-84782002000500024

11 Vasconcellos C.H.C. 2003. Hiperplasia mamária. In: Souza H.J.M. (Ed). Coletâneas em Medicina e Cirurgia Felina. Rio de Janeiro: L.F. Livros, pp.231-237.

12 Veiga G.A.L., Custódio S.R.B., Foz N.S.B. \& Vargas L.P. 2016. Hiperplasia fibroepitelial mamária em felino macho - relato de caso. In: Revista de Educação Continuada em Medicina Veterinária e Zootecnia do CRMV-SP. 14(2): 59-60. 